\title{
High Pressure Rheological Measurements of Gas
}

\section{Hydrate-in-Oil Slurries}

Yahua Qin ${ }^{1}$, Zachary M. Aman ${ }^{1}$, Paul F. Pickering ${ }^{2}$, Michael L. Johns ${ }^{1}$, Eric F. May ${ }^{1}$

1. Fluid Science and Resources Division, School of Mechanical and Chemical Engineering, University of Western Australia, 35 Stirling Highway, Crawley, WA 6009, AUSTRALIA

2. Woodside Energy Ltd., 240 St. Georges Terrace, Perth WA, 6000, AUSTRALIA

\begin{abstract}
Gas hydrates are ice-like solids that may form in crude oil flowlines under high pressure and at low temperature, resulting in the formation of viscous hydrate-laden oil slurries. The magnitude of the slurry viscosity has been suggested as a primary means of determining the risk and severity of flow blockage, but there is a dearth of data available to calibrate predictive models of hydrate-in-oil slurry viscosity. This work deploys a controlled-stress, high-pressure rheometer to characterize the rheological properties of methane hydrate-incrude oil slurries, which were generated in situ from water-in-oil emulsions. A vane blade rotor was found to maintain sufficient methane saturation in the oil phase during the hydrate growth period to allow near full conversion of the water. Dynamic measurements with the rheometer were able to separate the contributions to the viscosity change as the emulsion converted to a hydrate slurry due to (i) formation of the solid particles and (ii) reduction of the methane content in the oil continuous phase. For 5-30 vol\% watercut systems, the slurry viscosity increased between 20 and 60 times during hydrate growth, whereas, under equivalent conditions for a $20 \%$ watercut emulsion, the viscosity increase due to the desaturation of methane from the oil phase was less than a factor of two. The steady-state hydrate-in-oil slurry demonstrated shear thinning behavior at both 1 and $5{ }^{\circ} \mathrm{C}$. The measured slurry relative viscosity deviated between 12 and $212 \%$ from the current industry-standard hydrate-in-oil slurry viscosity model, indicating the need for model improvement. After an eight-hour annealing period to simulate subsea shut-in, the yield stress of the hydrate-in-oil slurries varied between 3 and $25 \mathrm{~Pa}$ over 5 to 25 vol\% hydrate.
\end{abstract}

Keywords: gas hydrates, slurry viscosity, particle aggregation, flow assurance 


\section{INTRODUCTION}

Natural gas hydrates are ice-like solid inclusion compounds that will form at high pressure and low temperature when certain small molecules, such as methane, ethane, and propane are available to be trapped in water cages with common patterns of structure I (e.g. from methane and ethane) and structure II (e.g. from propane and mixed gas system) [1]. In subsea oil and gas flowlines, such conditions may readily be achieved during transient operations where fluids cool into the hydrate stability region. Hydrates have an undesirable effect on the production and transportation of oil and gas, because, in sufficient quantity, they may increase frictional pressure losses and halt production in extreme scenarios [2]. This process was illustrated by Turner [3] with a four-step mechanism (Figure 1): (i) water entrainment in the oil phase [4], (ii) hydrate shell growth at the oil-water interface [5], (iii) aggregation of particles [6], and (iv) jamming-type failure [7].

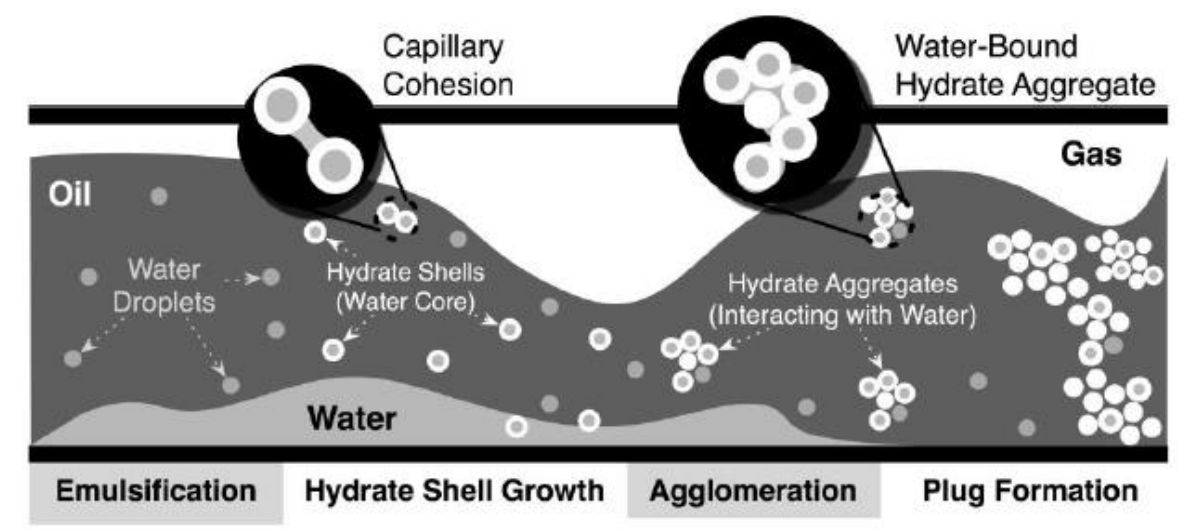

Figure 1. Conceptual model of hydrate formation reproduced from Aman et al. [8], agglomeration and plugging in a water-in-oil emulsified system under flowing conditions, originally developed by Turner in collaboration with J. Abrahamson [3].

To maximize production in crude oil flowlines, it is important to reliably determine (i) whether hydrates are thermodynamically stable and (ii) the extent to which hydrate particles may hinder flow. To address this second knowledge gap, engineers must have confidence in hydrate-in-oil slurry rheology models. When coupled with a transient multiphase flow simulator, this predictive capability may be used to assess whether sufficient energy is available to maintain flow inside the hydrate formation region. In the limit of insufficient energy, the hydrate-in-oil slurry velocity may approach a static condition, providing a physical basis for assessing the hydrate blockage risk.

Over the past 20 years, only limited research on the rheology of hydrate-in-oil slurries has been presented in the literature. In terms of the apparatus used, previous work may be 
generally classified into either flowloop- or benchtop rheometer-based studies. Flowloops are able to approximate the turbulent behavior of industrial pipelines, but several assumptions are required to estimate the apparent slurry viscosity from the measured pressure drop signal. Conversely, benchtop rheometers may be used to generate a well-characterized shear field, allowing the direct measurement of shear rate, shear stress and hence the slurry viscosity. Previous benchtop rheometer studies fall into one of three categories: (i) measurements of hydrate slurry formed within an autoclave or other equipment that is transferred into a rheometer for detailed characterization [9]; (ii) in situ measurements performed with model systems consisting of ambient pressure-forming hydrate guests, such as cyclopentane [10-12] or tetra-n-butyl ammonium bromide (TBAB) [13]; or (iii) in situ high-pressure measurements using a cup-and-bob geometry [14-16]. The first approach is intrinsically limited in that the hydrate aggregate structure may be changed or destroyed during the transfer process. The second approach does not allow for the quantification of hydrate volume fraction during the hydrate growth phase; such data only allow for qualitative interpretation. The third approach is equally limited, as the cup-and-bob geometry does not introduce sufficient shear at the gasoil interface to maintain gas saturation in the crude oil during hydrate formation [14-16]; as a consequence, the measured rheological phenomena may not be ascribed to a specific hydrate volume fraction, which precludes the ability to incorporate such results into a predictive model. Therefore, the first objective of the present investigation was to deploy a vane-blade mixing geometry in a controlled-stress, high-pressure rheometer, to enable a direct coupling between the apparent hydrate-in-oil slurry viscosity and the hydrate volume fraction throughout the water conversion process.

Publications regarding hydrate-in-oil slurry rheology mainly focus on two aspects: the steady-state hydrate slurry flowing viscosity and the yield stress. For the steady-state flowing viscosity, Jerbi et al. [17, 18] continued the research of Delahaye et al. [19, 20] to derive an empirical rheological model [21]. While an empirical approach may provide an easily calculable first approximation for estimating the slurry viscosity over a limited range of conditions, a predictive model based on fundamental principles is ultimately required to cover the breadth of industrial applications. The first attempt at such a predictive model was presented in 2002 by Camargo and Palermo [22], who deployed both a flowloop and a benchtop rheometer to characterize natural gas hydrate slurries formed from water-in-crude oil emulsions; this work was more fully detailed by Sinquin et al. [23]. These initial studies provided a novel method to estimate hydrate-in-oil slurry relative viscosity, where an orthokinetic flocculation model was incorporated within Mills' framework for suspension viscosity [24]. However, this model was only validated against two experimental datasets, and has not received further validation to date. Consequently, the second objective of the present study was to measure and characterize the apparent slurry viscosity over a wide range of shear rates, to determine whether the more fundamental modelling approach introduced by Camargo and Palermo [22] may be deployed reliably within hydrate-in-oil pipeline simulations.

In addition to steady-state flowing viscosity, hydrate-in-oil slurries are likely to experience a range of shear stress conditions in the pipeline, particularly during transient (shut-in and 
restart) operations. Darbouret et al. [25] studied the rheological properties of TBAB hydrate suspensions and observed Bingham plastic behavior, which was in agreement with measurements by Wenji et al. [26]. Webb et al. [14-16] measured the yield stress of methane hydrate-in-oil slurries, which increased directly with hydrate volume fraction over an eighthour annealing period. Currently, there are insufficient data in the literature to propose a general yield stress model for hydrate-in-oil slurries. The third objective of the present study was thus to measure the yield stress of high-pressure hydrate-in-oil slurries in which the hydrate volume fraction was known, as a first step toward the generation of a yield stress model for multiphase pipeline simulations.

\section{METHODS}

\subsection{Emulsion Preparation and Characterization}

Water-in-oil emulsions were created with deionized water and an industrial crude oil previously described by Aman et al. [27, 28] with a respective density and viscosity of 0.85 $\mathrm{g} / \mathrm{ml}$ and $4.7 \mathrm{cP}$ at $20{ }^{\circ} \mathrm{C}$ and atmosphere pressure. Asphaltenes are contained in this crude oil, which contributes to the stabilization of the water-in-oil emulsion. According to the procedures developed by Pradilla et al. [29], the concentration was detected to be $0.31 \mathrm{wt} \%$ in this crude oil. To generate the emulsions, water was added drop-wise to the oil phase under continuous homogenization at 17,500 RPM, according to the procedure described by Sjöblom et al. [30]; the emulsions were all sheared for 300 seconds to ensure the total kinetic energy input to the system was constant. Emulsion samples were left to ripen for two hours prior to use in the rheometer. The present study used watercuts of $0.05,0.1,0.2$, and 0.3 , which are defined herein as the volume fraction of water in the water-in-oil emulsion. These watercut values were selected to maintain homogeneity within, and stability of, the emulsion over the timescale of experiment; with respect to the crude oil used, higher watercut values $(>0.5)$ result in visible water clarification within 24 hours.

To determine whether the emulsions remained stable throughout the rheology measurements, low magnetic-field nuclear magnetic resonance (NMR) was used to monitor the water-in-oil droplet size distribution. The emulsion was sampled immediately after mixing and after each procedural step, including emulsification, ripening, rheological testing (involving hydrate formation and dissociation), and sample depressurization. An ACT-Aachen (now Magritek) $1 \mathrm{~T}$ Halbach Array permanent magnet and spectrometer, with a $1 \mathrm{~T} / \mathrm{m}$ magnetic field gradient, were used to monitor the droplet size distribution of each sample according to the procedure described by Johns et al. [31-33]. Figure 2 shows droplet size distributions for watercuts of $0.1,0.2$, and 0.3 before and after the corresponding rheological tests, with two repeat trials in each case. In all three systems, the results indicate excellent repeatability and show that systems at 0.1 and 0.2 watercut experience a slight degree of destabilization due to hydrate formation and dissociation; in both systems, the mean droplet size increased by approximately $5 \mu \mathrm{m}$ over the measurement period. At 0.3 watercut, the mean droplet size increased from 3 to $30-60 \mu \mathrm{m}$, suggesting a moderate degree of destabilization due to the 
measurement; this result provides context for the measured variance in suspension viscosity behavior discussed below.

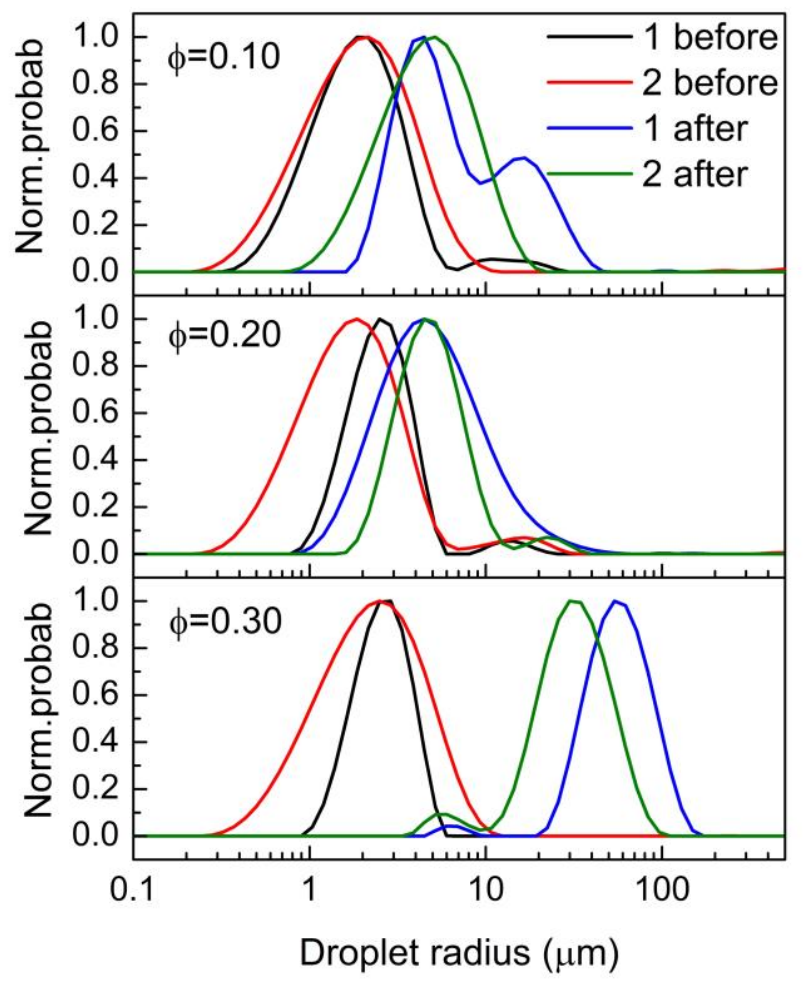

Figure 2. NMR droplet size distributions for two repeat emulsions before hydrate formation (red and black curves) and after hydrate dissociation (blue and green curves) for 0.10, 0.20, and 0.30 watercut.

\subsection{High Pressure Hydrate Rheometer}

A controlled-stress rheometer with a high-pressure cell was the primary apparatus used for this investigation, which included a chiller, a syringe pump and a gas manifold (Figure 3). Measurements were performed using a Discovery Hybrid Rheometer (DHR-3) from TA Instruments, where the high-pressure system contained a stainless-steel cell, rotor, and magnetic coupling assembly rated to $13.8 \mathrm{MPa}$. The high-pressure cell was enclosed by a Peltier jacket capable of achieving a temperature range of -10 to $150{ }^{\circ} \mathrm{C}$, which was connected to a heat sink cooled by the chiller, which was set at a constant temperature of $1{ }^{\circ} \mathrm{C}$. In these experiments, a vane-blade rotor was used to measure the apparent viscosity of the suspensions during and after hydrate formation. A syringe pump was connected to the rheometer to provide a constant initial pressure during the saturation of the oil phase. Although the assembly is capable of growing hydrate under isobaric conditions, hydrate was formed along an isochoric pathway for this study to mimic the decreasing pressure condition experienced by reacting hydrate-in-oil slurries during transport through the pipeline.

Although structure II hydrate occurs more often in oil and gas pipelines, structure I does still form in high methane fields. Furthermore, the rheology of structure I is likely to be similar to that of structure II hydrates. The use of pure methane has the additional advantage of improved experimental control through the avoidance of gas denuding (compositional 
variation) effects during hydrate formation. Methane hydrate equilibrium conditions were calculated using the Gibbs Energy Minimization model implemented in the software package CSMGem [34, 35] during the experiment, to ensure the reacting hydrate slurry had reached an equilibrium condition prior to the rheological characterization tests.

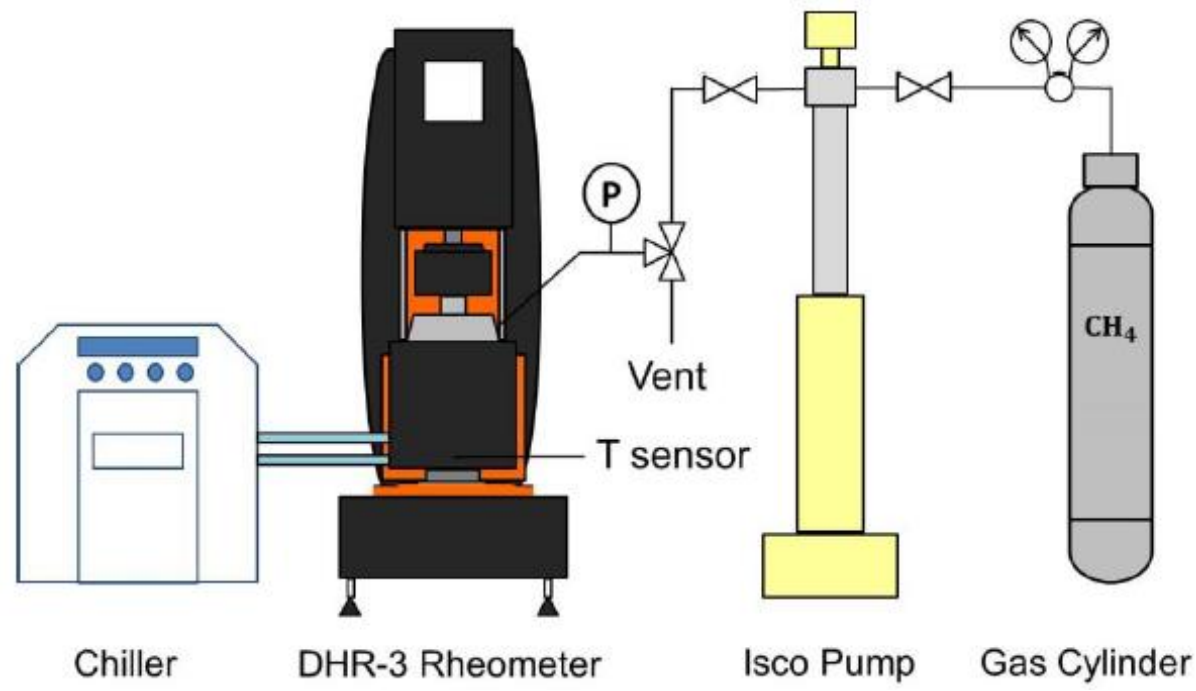

Figure 3. Schematic of the high-pressure rheometer assembly.

The vane-blade rotor used in the present study was inserted into the high-pressure cell and magnetically coupled to the mixing shaft. Compared to a cup-and-bob geometry, the vaneblade system can ensure the methane concentration of the water-in-oil emulsion does not become insufficient during hydrate growth and thereby limit water conversion. Consequently, the extent of hydrate growth in the sample was quantified from the decreasing pressure signal. Preliminary trials demonstrated that, at the highest shear rate of $217 \mathrm{~s}^{-1}$, a 0.3 watercut emulsion was saturated with $10 \mathrm{MPa}$ of methane within 15 minutes of mixing at ambient temperature (Figure 4). The rapid decrease in oil viscosity during gas saturation may be the result of secondary axial flows caused by the vane blades. The extent to which axial flow will increase energy dissipation and apparent viscosity is not well-established for this mixing geometry, and represents an additional contribution to the uncertainty of the measurements $[36,37]$. As a first approximation, the fluid calibration presented below may account for the secondary contribution of axial flow in the systems of interest. 


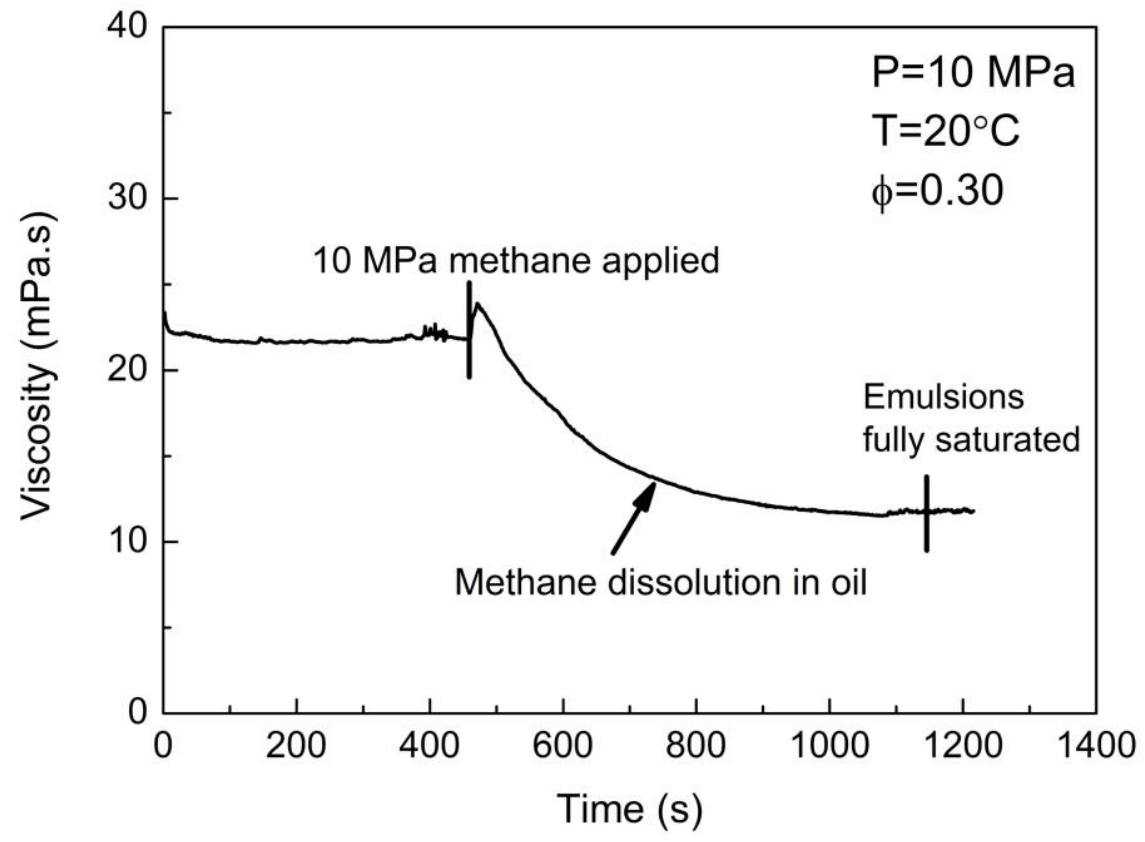

Figure 4. Example water-in-oil emulsion viscosity profile during methane saturation, which was initiated at approximately 450 seconds and required approximately 750 seconds to reach steady-state at a shear rate of $217 \mathrm{~s}^{-1}$.

To determine the shear rate and viscosity generated by the vane-blade rotor, the results were interpreted through the Couette analogy, which considers the rotor as if it were effectively a concentric cylinder able to generate the same torque as the vane-blade rotor at the same rotational speed. This method was first illustrated systematically by Bousmina et al. [38], with an extended description provided by Aït-Kadi et al. [39]. Specifically, the radius of the equivalent inner cylinder $\left(R_{i}\right)$ was calculated with equation (1):

$$
R_{i}=\frac{R_{e}}{\left(1+\frac{4 \pi \dot{N}}{n}\left(\frac{2 \pi M L R_{e}^{2}}{\Gamma}\right)^{1 / n}\right)^{n / 2}}
$$

where $R_{e}$ is the radius of the cup, $L$ is the length of the vane blade, $\Gamma$ is the measured torque applied to the vane blade, $\dot{N}$ is the rotational speed, and $M$ and $n$ are the consistency and the flow index of the power law model, as given by equation (2):

$$
\eta(\dot{\gamma})=M(\dot{\gamma})^{(n-1)}
$$

Here, $\eta$ is the viscosity and $\dot{\gamma}$ is the shear rate. According to the analysis of Bousmina et al. [38], in the case of a narrow gap $\left[\epsilon=\left(R_{e}-R_{i}\right) / R_{i} \ll 1\right]$, equation (3) holds:

$$
(1+\epsilon)^{2 / n}=1+\frac{2 \epsilon}{n}\left(1+\left(\frac{1}{n}-\frac{1}{2}\right) \epsilon\right)
$$


which finally results in a shear rate evaluated at $r^{*}=\left(R_{i}+R_{e}\right) / 2$ that is independent of the index $n$. In this limiting case, the Newtonian equivalent expression for $r^{*}$ can be applied to a fluid with unknown rheological behavior, and the shear rate and viscosity are given by equations (4) and (5), respectively:

$$
\begin{aligned}
\dot{\gamma}\left(r^{*}\right) & =4 \pi \dot{N} \frac{R_{e}^{2} R_{i}^{2}}{r^{* 2}\left(R_{e}^{2}-R_{i}^{2}\right)} \\
\eta & =\frac{\Gamma}{\dot{N}} \frac{\left(R_{e}^{2}-R_{i}^{2}\right)}{8 \pi^{2} L R_{e}^{2} R_{i}^{2}}
\end{aligned}
$$

The diameter of the cup $\left(R_{e}\right)$ used in this research was $14 \mathrm{~mm}$. The radius and length of the vane blade were $13 \mathrm{~mm}$ and $44 \mathrm{~mm}$, respectively. Seven standard Newtonian fluids with viscosities ranging from 16.75 to $1090 \mathrm{mPa} \cdot \mathrm{s}$ were used for direct calibration; the corresponding torque at each rotational speed was recorded by the rheometer. The values for $R_{i}$ and $R_{e}-R_{i} / R_{i}$ at each viscosity are shown in Table 1 . It is obvious that the gap [ $\epsilon=$ $\left(R_{e}-R_{i}\right) / R_{i}$ ] in this system is approximately equal to 0.2 . In order to confirm it is small enough for the measurement in this work, the deviation between $(1+\epsilon)^{2 / n}$ and $1+\frac{2 \epsilon}{n}(1+$ $\left(\frac{1}{n}-\frac{1}{2}\right) \epsilon$ ) was confirmed to be within 0.53 and $5.4 \%$, with the flow index $n$ ranging from 0.35 to 0.65 , which covers the hydrate slurry flow index vales detected in this research (Table 2 ). This calculation provides a validation that the gap used with the vane-blade rotor was sufficiently small to support the use of the Couette analogy described above. An average value of $R_{i}$ was then used to calculate the measured viscosity according to equation (5). As shown in Table 1, the relative deviation between the measured and calibrant viscosity was found to be within $6 \%$, which suggests the value of $R_{i}$ may be reasonable for this vane-blade rotor.

Table 1. Radius of the equivalent inner cylinder, $\mathrm{R}_{\mathrm{i}}$, for calibration fluids with different viscosity, together with the viscosity and errors obtained with the average value of $R_{i}$ used.

\begin{tabular}{cccccccc}
\hline $\begin{array}{c}\text { Calibrant Viscosity } \\
(\mathrm{mPa} \cdot \mathrm{s})\end{array}$ & 16.75 & 42.34 & 85.66 & 173.1 & 435.1 & 538.0 & 1090 \\
\hline$R_{i}(\mathrm{~mm})$ & 11.71 & 11.77 & 11.82 & 11.82 & 11.85 & 11.84 & 11.77 \\
$\left(R_{e}-R_{i}\right) / R_{i}$ & 0.1956 & 0.1895 & 0.1844 & 0.1844 & 0.1814 & 0.1824 & 0.1895 \\
$\begin{array}{c}\text { Measured Viscosity } \\
(\mathrm{mPa} \cdot \mathrm{s})\end{array}$ & 15.84 & 41.81 & 87.17 & 175.1 & 447.8 & 552.5 & 1070 \\
$\begin{array}{c}\text { Error }\left(\eta_{\text {meas }}-\eta_{\text {cal }}\right) \\
(\mathrm{mPa})\end{array}$ & -0.9063 & -0.5263 & +1.513 & +2.027 & +12.72 & +14.49 & -19.76 \\
Relative Error $(\%)$ & -5.410 & -1.243 & +1.766 & +1.171 & +2.924 & +2.693 & -1.813 \\
\hline
\end{tabular}

\subsection{Experimental Procedure}

Once the emulsion was saturated with methane, the rheological properties of the suspension were measured under three protocols: (i) the apparent viscosity was measured during the 
hydrate growth period at a constant shear rate, until the system reached a steady-state condition; (ii) flow curves were collected over the range of accessible shear rates for the fully-converted hydrate-in-oil suspension; and (iii) the yield stress of the slurry was measured after an eight-hour simulated shut-in condition. The following procedure was used in each trial:

1. The methane-saturated emulsion was cooled isochorically from $20^{\circ} \mathrm{C}$ and $10 \mathrm{MPa}$ to $1{ }^{\circ} \mathrm{C}$ at $0.5^{\circ} \mathrm{C} / \mathrm{min}$ to generate a driving force for hydrate formation. The shear rate during this process is $43.5 \mathrm{~s}^{-1}$.

2. The apparent suspension viscosity was measured during the hydrate growth period under a constant shear rate $\left(43.5 \mathrm{~s}^{-1}\right)$; the measurement continued for 12 hours after the pressure signal reached steady-state, to ensure the primary hydrate growth period had reached completion.

3. A flow curve was measured at $1{ }^{\circ} \mathrm{C}$ for the steady-state hydrate-in-oil suspension, where the shear rate was decreased step by step from $43.5 \mathrm{~s}^{-1}$ to $4 \mathrm{~s}^{-1}$, taking 50 shear rate points per decade. The shear rate was then increased to $220 \mathrm{~s}^{-1}$ over 50 points, and then decreased again to $4 \mathrm{~s}^{-1}$ over 50 points. As the suspensions displayed varying degrees of thixotropy, the apparent suspension viscosity was monitored at each shear rate, and the steady-state value was used in the flow curve; steady-state was defined when the deviation between three sequential measurements was less than $5 \%$. Each measurement took 30 seconds, so each shear rate step took at least 90 seconds; if the deviation across three sequential values was higher than $5 \%$, the measurement continued until the deviation became lower than 5\%. In the limit of the apparatus resolution, continued oscillation occasionally resulted in continued oscillation of the signal; the average value over 180 seconds was used in these cases.

4. The system temperature was increased to $5{ }^{\circ} \mathrm{C}$ while the system was subject to a constant shear rate $\left(43.5 \mathrm{~s}^{-1}\right)$, and was then held at this condition for 30 minutes. After this period, the flow curve measurement described in step \#3 were performed again.

5. To simulate the effect of subsea shut-in, the hydrate slurry was then permitted to anneal at $5{ }^{\circ} \mathrm{C}$ for eight hours under $1 \mathrm{~Hz}$ frequency oscillations at $2 \%$ strain, according to the procedure described by Webb et al. [14].

6. After annealing, during which period the hydrate slurry structure strengthened because of the cohesion between hydrate particles, the yield stress of the hydrate-inoil suspension was measured by increasing the applied shear stress from 0.1 to $300 \mathrm{~Pa}$ over $1080 \mathrm{~s}$ at a constant temperature $\left(5^{\circ} \mathrm{C}\right)$; the analysis procedure for yield stress measurements is discussed below.

The amount of hydrate formed was estimated from the pressure drop in the cell at $1{ }^{\circ} \mathrm{C}$ before and after hydrate formation due to the consumption of methane. The moles amount of gas consumed, $n_{g}$, was calculated according to equation (6):

$$
n_{g}=\frac{P_{0} V_{0}}{Z_{0} R T_{0}}-\frac{P_{f} V_{0}}{Z_{f} R T_{0}}
$$


where $P_{0}$ and $P_{f}$ are the initial and final pressure values of the gas phase, $V_{0}$ is the volume of the gas phase, $Z_{0}$ and $Z_{f}$ are the gas compressibility factor values of initial and final pressure, $R$ is the gas constant and $T_{0}$ is the temperature during formation. Compressibility factors for methane were calculated using the equation of state [40].

As methane can occupy both cavities of structure I [2] an ideal guest/water ratio (hydration number) of 5.75 [1] was assumed as shown in equation (7), to enable calculation of the hydrate volume fraction $\Phi$ from $n_{g}$ using equation (8):

$$
\begin{gathered}
\mathrm{CH}_{4}+5.75 \cdot \mathrm{H}_{2} \mathrm{O} \rightarrow \mathrm{CH}_{4} \cdot 5.75 \mathrm{H}_{2} \mathrm{O} \\
\Phi=\frac{n_{g}\left(M_{m}+5.75 M_{w}\right) / \rho_{h}}{\frac{n_{g}\left(M_{m}+5.75 M_{w}\right)}{\rho_{h}}+V_{e}-\frac{5.75 n_{g} \cdot M_{w}}{\rho_{w}}}
\end{gathered}
$$

where $M_{m}$ and $M_{w}$ are the molecular weight of methane and water, $\rho_{h}$ is the hydrate density, $V_{e}$ is the volume of the emulsion added each test and $\rho_{w}$ is the water density.

\section{RESULTS AND DISCUSSION}

\subsection{Apparent Viscosity During Hydrate Growth}

An example of hydrate formation in a system with a watercut of 0.2 is shown in Figure 5, which illustrates the cell pressure, temperature, and apparent suspension viscosity as a function of time. Throughout this work, we define "relative viscosity" as the ratio of the apparent suspension viscosity according to equation 4 to the viscosity of the methanesaturated oil phase (i.e. without water), to enable comparison with the model by Camargo and Palermo mentioned above [22]. The viscosity of the methane-saturated oil at 1 and $5{ }^{\circ} \mathrm{C}$ was measured to be 20 and $11.5 \mathrm{mPa}$.s, respectively. 


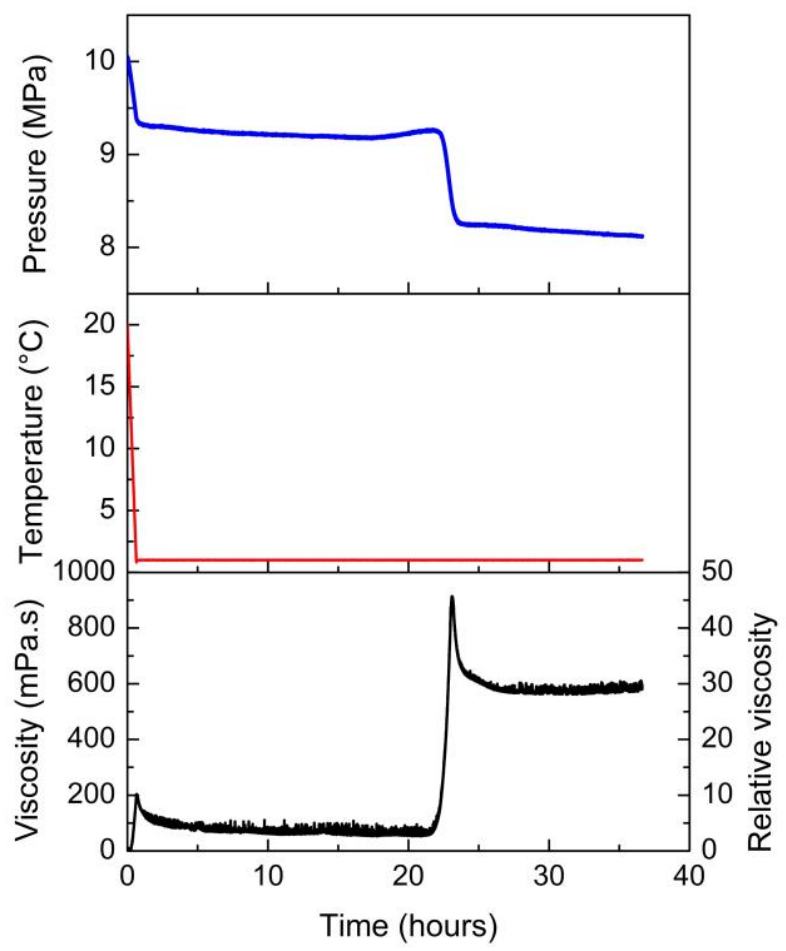

Figure 5. Pressure, temperature and viscosity profiles of a methane-saturated water-in-oil emulsion ( 0.20 watercut $)$ at a shear rate of $43.5 \mathrm{~s}^{-1}$, where hydrate formation was detected by a simultaneous decrease in pressure and increase in viscosity (21 hours).

The initial decrease in pressure and increase in viscosity shown in Figure 5 corresponds to cooling from 20 to $1^{\circ} \mathrm{C}$, without any hydrate formation even though the hydrate equilibrium temperature was $12.5^{\circ} \mathrm{C}$ [35]. At this subcooling, hydrate formation required approximately twenty-one hours ("induction time") and was detected by a sharp decrease in pressure with a corresponding increase in viscosity. Throughout the experimental campaign, variations in the induction time were observed as expected. Consistent with the observations of Webb et al. [14], the apparent suspension viscosity consistently increased by at least one order of magnitude during initial hydrate formation, with a gradual decrease to an intermediate viscosity with the application of continued shear in the cell.

To date, two potential mechanisms have been proposed to account for the large increase in apparent viscosity during initial hydrate formation, followed by the gradual decrease: (i) temporary de-saturation of the crude oil phase due to methane consumption [14], after which the methane was readily replenished as the hydrate reaction decreases; and (ii) strong capillary cohesion between hydrate particles from unconverted liquid water to form large aggregates [41], with the water availability and aggregate sizes both decreasing subsequently with continued hydrate growth [42].

For the system depicted in Figure 5, a second trial was performed to determine the contribution of the first mechanism (rapid de-saturation). Prior to hydrate nucleation, the high-pressure emulsion held at a constant temperature of $1{ }^{\circ} \mathrm{C}$ was depressurized using the ISCO pump from 9.4 to $8.1 \mathrm{MPa}$ at a rate identical to that measured in the hydrate formation 
trial. As shown in Figure 6, the emulsion viscosity did not change substantially during this depressurization period. The comparison between these data sets suggests that for this intermediate shear rate $\left(43.5 \mathrm{~s}^{-1}\right)$ and the hydrate growth rate observed in this system, the majority of the viscosity increase observed in Figure 5 was due to hydrate particle aggregation during the initial formation period.

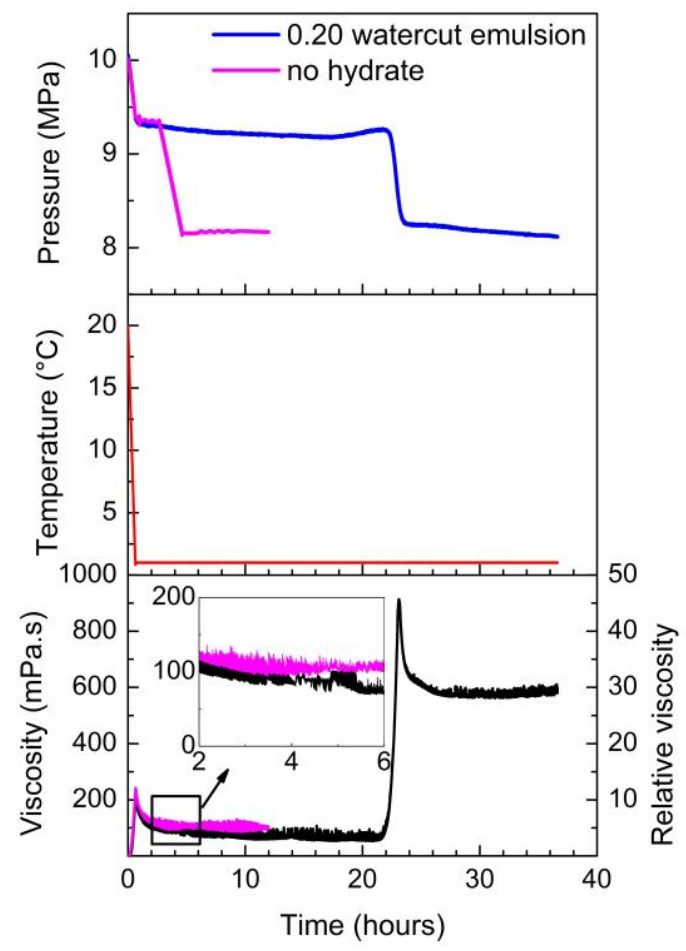

Figure 6. Pressure, temperature and viscosity profiles of a methane-saturated water-in-oil emulsion ( 0.20 watercut) at a shear rate of $43.5 \mathrm{~s}^{-1}$, with (black, blue) and without (pink) hydrate formation.

Figure 7 illustrates the evolution of apparent suspension viscosity and water conversion percentage during hydrate formation for systems at $0.05,0.1,0.2$, and 0.3 watercut. In each trial, the magnitude of the initial viscosity spike increased directly with watercut, and the suspension reached a steady-state condition approximately eight hours after hydrate formation. Independent repeat trials were performed at $0.1,0.2$ and 0.3 watercut, to provide a binary qualification of the uncertainty in the measured apparent suspension viscosity during the hydrate growth period. The results (Figure 7) illustrate the repeatability in both the maximum and steady-state apparent viscosity values at 0.1 and 0.2 watercut, with some moderate deviation between the data at 0.3 watercut. The deviations observed in apparent suspension viscosity at 0.3 watercut could be the consequence of a destabilizing suspension. At this higher watercut condition, there may be some water clarification at the bottom of the high-pressure cell causing a reduction in the measured apparent viscosity. NMR measurements (Figure 2) demonstrate that, at 0.3 watercut, the droplet sizes increased by approximately one order of magnitude after the experiment, suggesting that the water-in-oil emulsion partially destabilized over the measurement period. The viscosity increase 
measured after 4 hours in the second trial at 0.3 watercut may be the result of hydrate deposition on the cell wall.
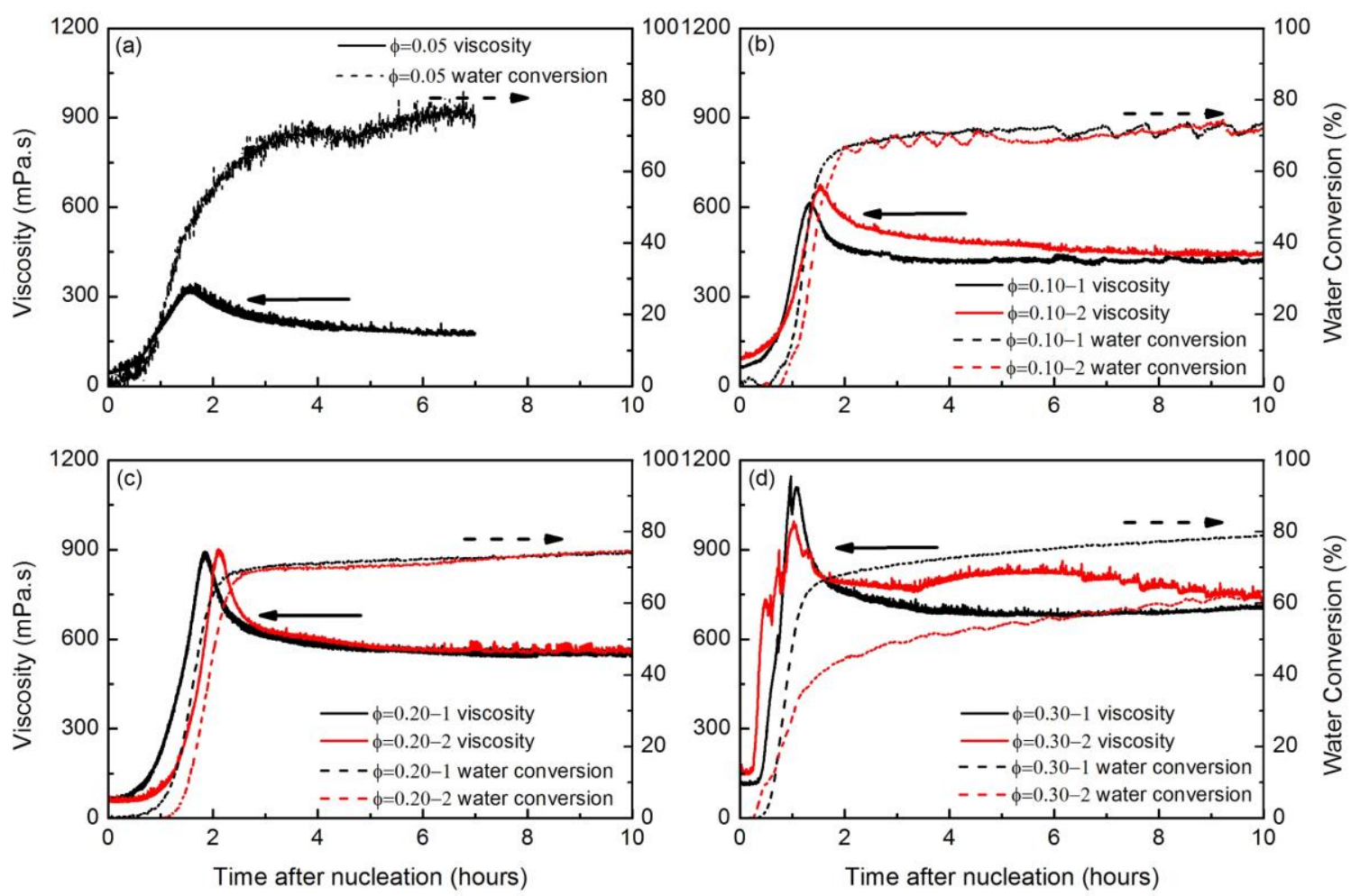

Figure 7. Apparent suspension viscosity and water conversion percentage as a function of time after hydrate growth for water-in-oil emulsions at (a) 0.05 , (b) 0.10 , (c) 0.20 , and (d) 0.30 watercut, at a constant temperature $\left(1^{\circ} \mathrm{C}\right)$, shear rate $\left(43.5 \mathrm{~s}^{-1}\right)$, and initial pressure $(10$ $\mathrm{MPa}$ at $20^{\circ} \mathrm{C}$ ); datasets in the panels for $0.1,0.2$, and 0.3 watercut represent independent repeat trials.

\subsection{Apparent Viscosity Dependence on Shear Rate}

After hydrate conversion reached a steady-state condition, flow curves were collected over the range of accessible shear rates for each watercut at temperatures of 1 and $5{ }^{\circ} \mathrm{C}$ (Figure 8). Three observations were derived from the data. First, the suspensions were shear thinning at each watercut. When fitting the viscosity as a function of the shear rate with a simple power law model, as shown in equation (2), the values of the flow behavior index, $n$, range from 0.35 to 0.65 , corresponding to a shear thinning suspension; the results are shown in Table 2 .

Table 2. Power law parameters for hydrate slurry flow curves formed from water-in-oil emulsions with different watercuts, corresponding to the data presented in Figure 8.

\begin{tabular}{c|c|l|c|c}
\hline Temperature & \multicolumn{2}{|c|}{ Watercut } & $m\left(\mathrm{mPa} \cdot \mathrm{s}^{n}\right)$ & $n$ \\
\hline \multirow{2}{*}{$1{ }^{\circ} \mathrm{C}$} & \multirow{2}{*}{0.05} & increasing shear & 680 & 0.59 \\
\cline { 3 - 5 } & & decreasing shear & 530 & 0.61 \\
\hline
\end{tabular}




\begin{tabular}{|c|c|c|c|c|}
\hline & \multirow{2}{*}{0.10} & increasing shear & 2200 & 0.41 \\
\hline & & decreasing shear & 2100 & 0.40 \\
\hline & \multirow{2}{*}{0.20} & increasing shear & 2700 & 0.52 \\
\hline & & decreasing shear & 2500 & 0.52 \\
\hline & \multirow{2}{*}{0.30} & increasing shear & 4000 & 0.49 \\
\hline & & decreasing shear & 3700 & 0.50 \\
\hline \multirow{8}{*}{$5^{\circ} \mathrm{C}$} & \multirow{2}{*}{0.05} & increasing shear & 340 & 0.62 \\
\hline & & decreasing shear & 280 & 0.64 \\
\hline & \multirow{2}{*}{0.10} & increasing shear & 2200 & 0.36 \\
\hline & & decreasing shear & 1900 & 0.37 \\
\hline & \multirow{2}{*}{0.20} & increasing shear & 1700 & 0.59 \\
\hline & & decreasing shear & 1600 & 0.58 \\
\hline & \multirow{2}{*}{0.30} & increasing shear & 2300 & 0.59 \\
\hline & & decreasing shear & 2100 & 0.58 \\
\hline
\end{tabular}

Second, hysteresis was observed at each watercut; in Figure 8, the filled data points correspond to increasing shear rate (i.e. from 4 to $220 \mathrm{~s}^{-1}$ ) and the open data points correspond to decreasing shear rate (i.e. from 220 to $4 \mathrm{~s}^{-1}$ ). In each case, at the same shear rate, the apparent viscosity obtained with deceasing shear rate was lower than that obtained during increasing shear rate; this observation could be the consequence of a reduction in the maximum aggregate size after experiencing the maximum shear rate condition, which may not readily re-establish itself upon reduction of the shear rate. The hysteresis observed in each indicates it may be important to track the shear history of each hydrate aggregate in multiphase pipe simulations.
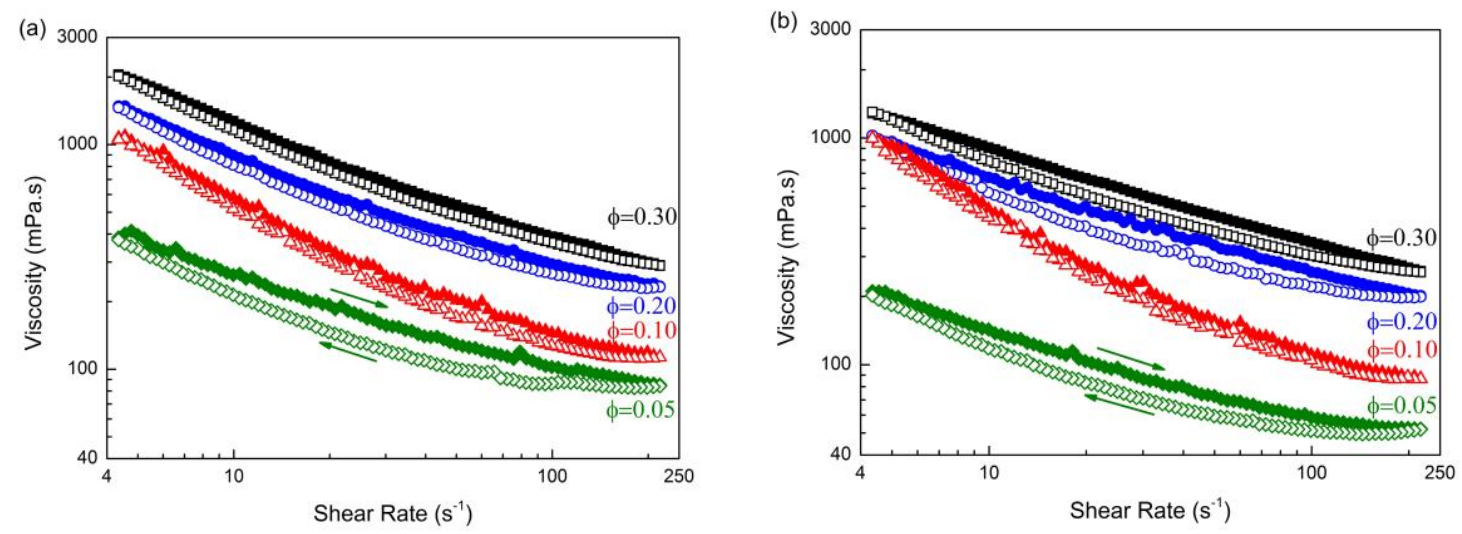

Figure 8. Steady state flow curves of hydrate slurries formed from water-in-oil emulsions with different watercuts at $1{ }^{\circ} \mathrm{C}$ (panel a) and $5{ }^{\circ} \mathrm{C}$ (panel b) formed from an initial methane pressure of $10 \mathrm{MPa}$. Filled data points indicate increasing shear rate, while open data points correspond to decreasing shear rate.

\subsection{Comparison to an Industrial Hydrate Slurry Rheology Model}

The current industry-standard approach to predicting hydrate slurry relative viscosity was presented by Camargo and Palermo [22], shown in Equations (9) to (11), who considered the size and volume fraction of hydrate aggregates in the oil phase. The model was derived from a simple force balance between hydrate cohesion, which acts to increase the mean aggregate 
diameter, and the shear stress applied by the continuous oil phase, which acts to reduce the mean aggregate diameter. The model is based on the assumption that hydrate particles behave as solid spheres with identical diameters to the water droplets. According to Haber et al. [43] who monitored the growing of hydrate shells with a low-field NMR apparatus, in the case that the initial water-in-oil emulsion has a droplet size distribution below approximately 100 $\mu \mathrm{m}$, it is reasonable to assume that these water droplets will be fully converted into hydrate particles without an internal water core, and that the hydrate volume fraction will be identical to the value calculated from water conversion. This assumption also applies to the present measurements as the water droplet size distribution is below $100 \mu \mathrm{m}$, as shown in Figure 2. Therefore, it is reasonable to regard the hydrate particle formed in this work as solid particles and the model of Camargo and Palermo [22] is applicable.

$$
\left(\frac{d_{A}}{d_{p}}\right)^{(4-f)}-\frac{F_{a}\left(1-\frac{\Phi}{\Phi_{\max }}\left(\frac{d_{A}}{d_{p}}\right)^{(3-f)}\right)^{2}}{d_{p}{ }^{2} \eta_{0} \dot{\gamma}\left(1-\Phi\left(\frac{d_{A}}{d_{p}}\right)^{(3-f)}\right)}=0
$$

Here, $d_{A}$ is the aggregate diameter; $d_{p}$ is the particle diameter; $f$ is a fractal dimension, which is reported to range from 2 to 2.7 for aggregates under shear conditions [44] and was taken as 2.5 by Camargo and Palermo [22]; $F_{a}$ is the force of cohesion between particles, and was assumed to be a constant $1.6 \mathrm{mN} / \mathrm{m}$ when reduced by the mean hydrate particle diameter [22]; $\Phi$ is the actual hydrate volume fraction; $\Phi_{\max }$ is the maximum packing volume fraction for hydrate particles, which was assumed to be 4/7 from Mills [24]; $\eta_{0}$ is the viscosity of dispersing liquid; and $\dot{\gamma}$ is the shear rate applied. In this predictive model, equation (9) is solved numerically for the mean aggregate diameter, which is deployed in equation (10) to calculate the effective volume fraction $\left(\Phi_{\text {eff }}\right)$.

If the force balance returns a positive aggregation state (i.e. $d_{A}$ is larger than $d_{p}$ ), the form of equation (10) demonstrates that the effective hydrate volume fraction will be larger than the actual (i.e. measured) volume fraction; simply, this relationship accounts for the occluded volume between individual hydrate particles due to particle aggregation. This effective volume fraction is then deployed within Mills' suspension viscosity model [24] to calculate the relative viscosity of the hydrate slurry, as shown in equation (11):

$$
\begin{gathered}
\Phi_{e f f}=\Phi\left(\frac{d_{A}}{d_{p}}\right)^{(3-f)} \\
\eta_{r}=\frac{1-\Phi_{e f f}}{\left(1-\frac{\Phi_{e f f}}{\Phi_{\max }}\right)^{2}}
\end{gathered}
$$

where $\eta_{r}$ is the relative viscosity, defined as the ratio between the apparent viscosity $\eta_{h y d}$ of the suspension and the viscosity of the dispersing liquid $\eta_{0}$. If the solution of equation (9) is 
$d_{A}<d_{p}, d_{A}$ is fixed equal to $d_{p}$ and the relative viscosity is calculated by equation (11) with $\Phi$ eff $=\Phi$.

The hydrate flow curves measured in this investigation were compared to the model predictions with the parameters set to the values or ranges assumed by Camargo and Palermo [22]. The particle diameter $d_{p}$ for each test was taken from the low-field NMR measurements and the particle volume fractions were calculated from the measured pressure drop and inferred gas consumption in the isochoric system during the hydrate growth period, as shown in Table 3. Finally, fractal dimension ranges from 1.3 to 2.7 were considered when comparing this model to experimental data to determine the best fit for low, average and high shear-rate data. Differences between the experimental data and the above model are shown in Figure 9, which presents the flow curves collected at $1{ }^{\circ} \mathrm{C}$; similar trends were observed at $5{ }^{\circ} \mathrm{C}$. The deviation between the experimental data and model predictions are reported in Table 4.

Table 3. Mean particle diameter and steady state hydrate particle volume fractions for different tests

\begin{tabular}{c|c|c|c|c}
\hline Water cut & 0.05 & 0.10 & 0.20 & 0.30 \\
\hline Hydrate volume fraction $\Phi$ & 0.039 & 0.081 & 0.164 & 0.220 \\
\hline $\begin{array}{c}\text { Mean particle diameter } d_{p} \\
(\mu \mathrm{m})\end{array}$ & 3.3 & 3.6 & 3.7 & 3.8 \\
\hline
\end{tabular}

Table 4. Deviation between experiment and model for flow curves of hydrate slurry formed from water-in-oil emulsions at $1{ }^{\circ} \mathrm{C}$ with different hydrate volume fraction

\begin{tabular}{c|c|c|c}
\hline $\begin{array}{c}\text { Hydrate volume } \\
\text { fraction } \Phi\end{array}$ & Shear Rate $\left(\mathrm{s}^{-1}\right)$ & $\begin{array}{c}f \\
\text { (best fit) }\end{array}$ & $\begin{array}{c}\text { Average Deviation Between } \\
\text { Model and Experiment }\end{array}$ \\
\hline \multirow{3}{*}{0.039} & 217 & 1.4 & $212 \%$ \\
\cline { 2 - 4 } & 4 to 217 & 2.2 & $19.8 \%$ \\
\cline { 2 - 4 } & 4 & 2.3 & $24.2 \%$ \\
\cline { 2 - 4 } 0.081 & 217 & 2.1 & $85.3 \%$ \\
\hline \multirow{2}{*}{0.164} & $4-217$ & 2.4 & $11.8 \%$ \\
\hline \multirow{2}{*}{0.220} & 217 & 2.3 & $24.0 \%$ \\
\cline { 2 - 4 } & $4-217$ & 2.6 & $133 \%$ \\
\hline
\end{tabular}

This is the first investigation following Camargo and Palermo's initial study [22] to benchmark the model performance, where the initial study was conducted over shear rates of $50 \mathrm{~s}^{-1}$ to $700 \mathrm{~s}^{-1}$ and the present work focused on a lower shear rate range ( 4 to $220 \mathrm{~s}^{-1}$ ). The poor performance of the model in this work may be due to a combination of (i) poor performance of the underlying slurry model, (ii) the continual use of an orthokinetic basis for calculating aggregate diameter, or (iii) an overly simplistic assumption of constant fractal 
dimension. As shear flow can break up the aggregation between the hydrate particles by increasing the shear force, the structure of the aggregates may tend to be more compact with increasing shear rate, which is in accordance with the theory that the aggregation transfers from perikinetic to orthokinetic when applied to shear conditions. Under this condition, the fractal dimension should increase [23], approaching a value of three at an infinite shear rate. This effect may be more pronounced in the low-shear region. However, as shown in Figure 9 , the trend of fractal dimension with shear rate obtained by fitting the data in fact displays the opposite trend. This suggests that the assumption of a fractal dimension as a simple constant exponent in the aggregation model is insufficient to represent data obtained under varying shear rates. It is clear that additional studies are required to determine a more suitable form of the aggregation model that is able to capture the changing morphology with shear rate[23]. The result also demonstrates that, in the context of industrial flow assurance, a comprehensive database of hydrate-in-oil slurry viscosities is required to validate the use of any predictive model.
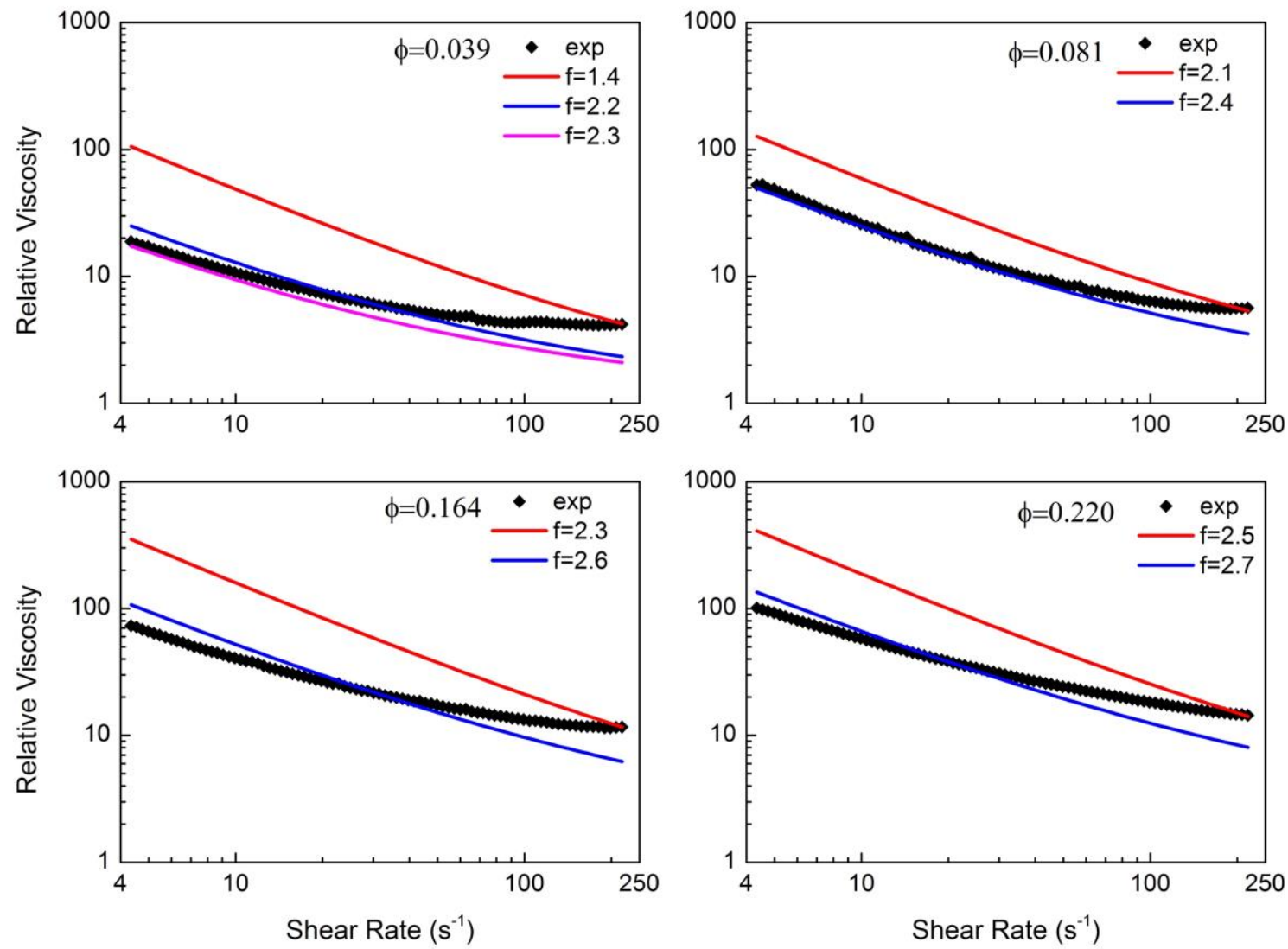

Figure 9. Comparison between experimental (black data points) flow curves and model predictions (curves) at four different hydrate volume fractions at $1{ }^{\circ} \mathrm{C}$, where the red lines correspond to predictions in which the fractal value was chosen to match the data measured at high shear rate, the blue line corresponds to the fractal value that matches the average shear rate data, and the pink line corresponds to the fractal value that matches the low shear rate data. 


\subsection{Yield Stress of Hydrate-in-Oil Slurries}

After an eight-hour annealing period, the yield stress of each hydrate-in-oil suspension was measured according to the above procedure $[16,45,46]$. An example measurement procedure is shown in Figure 10, where the yield stress was estimated to be approximately $25 \mathrm{~Pa}$ from the intersection of straight lines fitted to the two regions of the measured shear rate-shear stress curve: $\dot{\gamma}<0.01 \mathrm{~s}^{-1}$ and $0.01 \leq \dot{\gamma} \leq 30 \mathrm{~s}^{-1}$. At $\dot{\gamma}>30 \mathrm{~s}^{-1}$, the shear rate increased directly with shear stress, indicating the suspension flowed when subject to shear greater than this yield stress condition.
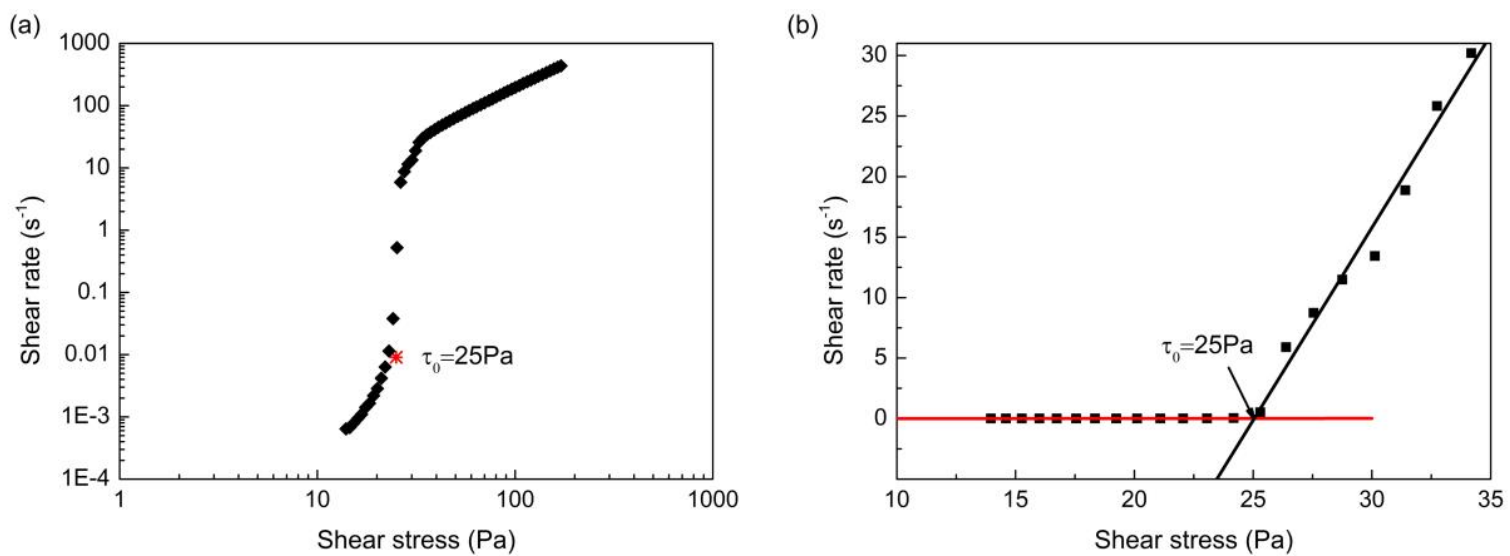

Figure 10. Hydrate-in-oil shear rate as a function of shear stress, which was increased at a rate of $1000 \mathrm{~Pa} / \mathrm{hr}$ to determine the yield stress of a 0.3 watercut system after an eight-hour annealing period.

Figure 11 compares the measured yield stress for 0.05 to 0.3 watercut systems at $5{ }^{\circ} \mathrm{C}$ to the data reported by Webb et al. [15] with a mineral oil at $0{ }^{\circ} \mathrm{C}$; the yield stress of ketchup, as reported by Benmouffok-Benbelkacem et al. [47] at $20^{\circ} \mathrm{C}$, is shown for comparative purposes. The yield stress value from this work shown in Figure 11 is the average value of independent repeat tests for each watercut and the error bars show the range of the measured values. The yield stresses measured in this study showed a similar trend with those reported by Webb et al. [15], which increased with increasing watercut. Also, the detection of yield stress at a low watercut of 5\% in in two completely independent experiments indicates that the measured yield stress may include contributions from both fractal aggregates and gravimetric settling. Further systematic studies are required to determine how the diversity of crude oil chemistry - particularly with respect to wax content - will affect the yield stress when hydrates are present. The results presented here and those of Webb et al. [15] indicate that hydrate-in-oil suspensions have a significant yield stress, which will affect the pressure driving force required to initiate flow in a given production system. This result is particularly critical to the future development of transient multiphase flow simulators, which currently do not account for yield stress when assessing the restart of crude oil systems containing hydrate. 


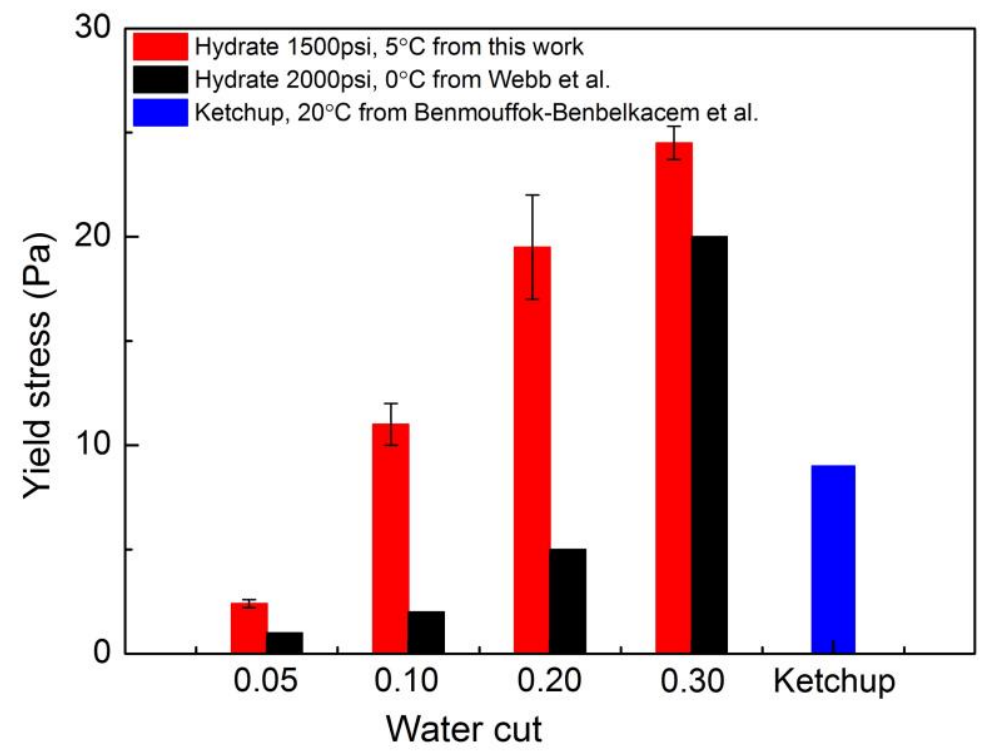

Figure 11. Measured yield stress (red) of hydrate-in-oil slurries formed from saturated waterin-oil emulsions with $0.05,0.10,0.20$ and 0.30 watercut, after an eight-hour annealing period at $5{ }^{\circ} \mathrm{C}$; the measurements are compared to hydrate-in-oil yield stress measurements from Webb et al. [15]. The yield stress of ketchup at $20^{\circ} \mathrm{C}$ [47] is shown for comparative purposes.

\section{CONCLUSIONS}

The rheology of hydrate slurries formed under high pressure from water-in-oil emulsions was measured with a controlled-stress rheometer using a vane-blade rotor to maintain oil saturation. Before and after rheological measurements, the droplet size distributions of the emulsions were characterized by low-field NMR. During hydrate formation in the rheometer at constant shear rate, methane hydrate growth was quantified through a decrease in the measured pressure under isochoric conditions, corresponding to an increase in the apparent suspension viscosity. The vane blade rotor was able to maintain saturation of the crude oil phase; the ability to maintain dissolved gas content suggests the presence of secondary axial flows, which may function to increase the apparent viscosity. As a first approximation, the vane blade rotor was calibrated against viscosity standards between 16.75 and $1090 \mathrm{mPa} \cdot \mathrm{s}$. For emulsions at 0.2 watercut, the apparent suspension viscosity increased up to 50 times during hydrate formation.

The flow curves for steady-state hydrate-in-oil slurries were measured at 1 and $5{ }^{\circ} \mathrm{C}$ after hydrate growth reached steady-state; the data illustrate that hydrate-in-oil slurries are shear thinning. Hysteresis was observed in each flow curve, which may be associated with hydrate aggregate breakup at high shear rate. After an eight-hour annealing period, the yield stress of hydrate-in-oil slurries varied between 3 and $25 \mathrm{~Pa}$ over a watercut range of 0.05 to 0.3 . The measured flow curves were compared to a current-generation industry rheological model for hydrate-in-oil slurries, which showed deviations between 12 and $212 \%$ over the range of 
shear rates studied. Deviation between the model and experiment increased as shear rate decreased, suggesting additional development is required in the low-shear rate region, which is critical to accurately predicting hydrodynamic behavior of fluids in subsea pipelines during shut-in and restart.

\section{Acknowledgements}

The authors acknowledge the Australian Research Council and Woodside Energy Ltd. for support of this work through Linkage project LP150100785. The purchase of the rheometer was supported in part by the National Geosequestration Laboratory (NGL).

\section{Reference}

[1] E.D. Sloan Jr, C. Koh, Clathrate hydrates of natural gases, CRC press, 2007.

[2] E.D. Sloan, C.A. Koh, A. Sum, Natural gas hydrates in flow assurance, Gulf Professional Publishing, 2010.

[3] D.J. Turner, Clathrate hydrate formation in water-in-oil dispersions, in, Colorado School of Mines Golden, CO, 2005.

[4] J.A. Boxall, C.A. Koh, E.D. Sloan, A.K. Sum, D.T. Wu, Droplet Size Scaling of Waterin-Oil Emulsions under Turbulent Flow, Langmuir, 28 (2012) 104-110.

[5] C.J. Taylor, K.T. Miller, C.A. Koh, E.D. Sloan Jr., Macroscopic investigation of hydrate film growth at the hydrocarbon/water interface, Chemical Engineering Science, 62 (2007) 6524-6533.

[6] Z.M. Aman, E.P. Brown, E.D. Sloan, A.K. Sum, C.A. Koh, Interfacial mechanisms governing cyclopentane clathrate hydrate adhesion/cohesion, Physical Chemistry Chemical Physics, 13 (2011) 19796-19806.

[7] P.G. Lafond, M.W. Gilmer, C.A. Koh, E.D. Sloan, D.T. Wu, A.K. Sum, Orifice jamming of fluid-driven granular flow, Phys. Rev. E, 87 (2013) 8.

[8] Z.M. Aman, K. Pfeiffer, S.J. Vogt, M.L. Johns, E.F. May, Corrosion inhibitor interaction at hydrate-oil interfaces from differential scanning calorimetry measurements, Colloids and Surfaces A: Physicochemical and Engineering Aspects, 448 (2014) 81-87.

[9] A. Memon, H.-J. Ng, Effectiveness of Low-Dosage Hydrate Inhibitors and their Rheological Behavior for Gas Condensate/Water Systems, Journal of Chemical \& Engineering Data, 60 (2014) 293-298.

[10] G. Zylyftari, J.W. Lee, J.F. Morris, Salt effects on thermodynamic and rheological properties of hydrate forming emulsions, Chemical Engineering Science, 95 (2013) 148-160. [11] A. Ahuja, G. Zylyftari, J.F. Morris, Yield stress measurements of cyclopentane hydrate slurry, Journal of Non-Newtonian Fluid Mechanics, (2014).

[12] A. Ahuja, G. Zylyftari, J.F. Morris, Calorimetric and Rheological Studies on Cyclopentane Hydrate-Forming Water-in-Kerosene Emulsions, Journal of Chemical \& Engineering Data, (2014).

[13] S. Hashimoto, K. Kawamura, H. Ito, M. Nobeoka, K. Ohgaki, Y. Inoue, Rheological study on tetra-n-butyl ammonium salt semi-clathrate hydrate slurries, in: Proceedings of Seventh International Conference on Gas Hydrates, Edinburgh, Scotland, United Kingdom, 2011. 
[14] E.B. Webb, P.J. Rensing, C.A. Koh, E.D. Sloan, A.K. Sum, M.W. Liberatore, HighPressure Rheology of Hydrate Slurries Formed from Water-in-Oil Emulsions, Energy \& Fuels, 26 (2012) 3504-3509.

[15] E.B. Webb, C.A. Koh, M.W. Liberatore, Rheological Properties of Methane Hydrate Slurries Formed From AOT plus Water plus Oil Microemulsions, Langmuir, 29 (2013) 10997-11004.

[16] E.B. Webb, C.A. Koh, M.W. Liberatore, High Pressure Rheology of Hydrate Slurries Formed from Water-in-Mineral Oil Emulsions, Industrial \& Engineering Chemistry Research, 53 (2014) 6998-7007.

[17] S. Jerbi, A. Delahaye, L. Fournaison, P. Haberschill, Characterization of $\mathrm{CO}<\mathrm{sub}>$ $2</$ sub $>$ hydrate formation and dissociation kinetics in a flow loop, International journal of refrigeration, 33 (2010a) 1625-1631.

[18] S. Jerbi, A. Delahaye, L. Fournaison, P. Haberschill, N. Mayoufi, Design of a new circulation loop based on CO2 hydrate kinetics, Sustainable Refrigeration and Heat Pump Technology, KTH, Stockholm, (2010b).

[19] A. Delahaye, L. Fournaison, S. Marinhas, M.C. Martinez, Rheological study of CO2 hydrate slurry in a dynamic loop applied to secondary refrigeration, Chemical Engineering Science, 63 (2008) 3551-3559.

[20] A. Delahaye, L. Fournaison, S. Jerbi, N. Mayoufi, Rheological properties of CO2 hydrate slurry flow in the presence of additives, Industrial \& Engineering Chemistry Research, 50 (2011) 8344-8353.

[21] S. Jerbi, A. Delahaye, J. Oignet, L. Fournaison, P. Haberschill, Rheological properties of $\mathrm{CO}<\mathrm{sub}>2</ \mathrm{sub}>$ hydrate slurry produced in a stirred tank reactor and a secondary refrigeration loop, International Journal of Refrigeration, 36 (2013) 1294-1301.

[22] R. Camargo, T. Palermo, Rheological Properties of Hydrate Suspensions in an Asphaltenic Crude Oil, in: 4th International Conference on Gas Hydrates, 2002.

[23] A. Sinquin, T. Palermo, Y. Peysson, Rheological and flow properties of gas hydrate suspensions, Oil \& gas science and technology, 59 (2004) 41-57.

[24] P. Mills, Non-Newtonian behaviour of flocculated suspensions, Journal de Physique Lettres, 46 (1985) 301-309.

[25] M. Darbouret, M. Cournil, J.-M. Herri, Rheological study of TBAB hydrate slurries as secondary two-phase refrigerants, International Journal of Refrigeration, 28 (2005) 663-671.

[26] S. Wenji, X. Rui, H. Chong, H. Shihui, D. Kaijun, F. Ziping, Experimental investigation on TBAB clathrate hydrate slurry flows in a horizontal tube: Forced convective heat transfer behaviors, international journal of refrigeration, 32 (2009) 1801-1807.

[27] Z.M. Aman, K. Pfeiffer, S.J. Vogt, M.L. Johns, E.F. May, Corrosion inhibitor interaction at hydrate-oil interfaces from differential scanning calorimetry measurements, Colloids and Surfaces A: Physicochemical and Engineering Aspects, 448 (2014) 81-87.

[28] Z.M. Aman, A. Haber, N.N.A. Ling, A. Thornton, M.L. Johns, E.F. May, Effect of Brine Salinity on the Stability of Hydrate-in-Oil Dispersions and Water-in-Oil Emulsions, Energy $\&$ Fuels, (2015).

[29] D. Pradilla, S. Simon, J. Sjöblom, Mixed interfaces of asphaltenes and model demulsifiers part I: Adsorption and desorption of single components, Colloids and Surfaces A: Physicochemical and Engineering Aspects, 466 (2015) 45-56.

[30] J. Sjöblom, B. Øvrevoll, G. Jentoft, C. Lesaint, T. Palermo, A. Sinquin, P. Gateau, L. Barré, S. Subramanian, J. Boxall, S. Davies, L. Dieker, D. Greaves, J. Lachance, P. Rensing, K. Miller, E.D. Sloan, C.A. Koh, Investigation of the Hydrate Plugging and Non-Plugging Properties of Oils, Journal of Dispersion Science and Technology, 31 (2010) 1100-1119. [31] M.L. Johns, NMR studies of emulsion, Current Opinion in Colloid \& Interface Science, 14 (2009) 178-183. 
[32] N.N.A. Ling, A. Haber, E.F. May, E.O. Fridjonsson, M.L. Johns, NMR studies of emulsion microstructure approaching the phase inversion point, Colloids and Surfaces A: Physicochemical and Engineering Aspects, 462 (2014) 244-251.

[33] E.O. Fridjonsson, B.F. Graham, M. Akhfash, E.F. May, M.L. Johns, Optimized Droplet Sizing of Water-in-Crude Oil Emulsions Using Nuclear Magnetic Resonance, Energy \& Fuels, 28 (2014) 1756-1764.

[34] A.L. Ballard, E.D. Sloan, The next generation of hydrate prediction: Part III. Gibbs energy minimization formalism, Fluid Phase Equilibria, 218 (2004) 15-31.

[35] A.L. Ballard, E.D. Sloan, The next generation of hydrate prediction. IV: A comparison of available hydrate prediction programs, Fluid Phase Equilibria, 216 (2004) 257-270.

[36] H.A. Barnes, J.O. Carnali, The vane - in - cup as a novel rheometer geometry for shear thinning and thixotropic materials, Journal of Rheology, 34 (1990) 841-866.

[37] H.A. Barnes, Q.D. Nguyen, Rotating vane rheometry-a review, Journal of NonNewtonian Fluid Mechanics, 98 (2001) 1-14.

[38] M. Bousmina, A. Ait-Kadi, J. Faisant, Determination of shear rate and viscosity from batch mixer data, Journal of Rheology (1978-present), 43 (1999) 415-433.

[39] A. Aï - Kadi, P. Marchal, L. Choplin, A.S. Chrissemant, M. Bousmina, Quantitative Analysis of Mixer - Type Rheometers using the Couette Analogy, The Canadian Journal of Chemical Engineering, 80 (2002) 1166-1174.

[40] U. Setzmann, W. Wagner, A new equation of state and tables of thermodynamic properties for methane covering the range from the melting line to $625 \mathrm{~K}$ at pressures up to $100 \mathrm{MPa}$, Journal of Physical and Chemical Reference Data, 20 (1991) 1061-1155.

[41] Z.M. Aman, E.P. Brown, E.D. Sloan, A.K. Sum, C.A. Koh, Interfacial mechanisms governing cyclopentane clathrate hydrate adhesion/cohesion, Physical Chemistry Chemical Physics, (2011) 19796-19806.

[42] R. Larsen, A. Lund, C.B. Argo, Cold flow-a practical solution, in: Proc. of the 11th International Conference on Multiphase Flow, June, San Remo, Italy, 2003.

[43] A. Haber, M. Akhfash, K. Loh, Z.M. Aman, E.O. Fridjonsson, E.F. May, M.L. Johns, Monitoring of Hydrate Shell Growth using NMR Techniques, Langmuir, 31 (2015) 87868794.

[44] L.L. Hoekstra, R. Vreeker, W.G.M. Agterof, Aggregation of colloidal nickel hydroxycarbonate studied by light scattering, Journal of Colloid and Interface Science, 151 (1992) 17-25.

[45] P.J. Rensing, M.W. Liberatore, A.K. Sum, C.A. Koh, E.D. Sloan, Viscosity and yield stresses of ice slurries formed in water-in-oil emulsions, Journal of Non-Newtonian Fluid Mechanics, 166 (2011) 859-866.

[46] A. Ahuja, G. Zylyftari, J.F. Morris, Yield stress measurements of cyclopentane hydrate slurry, Journal of Non-Newtonian Fluid Mechanics, 220 (2015) 116-125.

[47] G. Benmouffok-Benbelkacem, F. Caton, C. Baravian, S. Skali-Lami, Non-linear viscoelasticity and temporal behavior of typical yield stress fluids: Carbopol, Xanthan and Ketchup, Rheologica acta, 49 (2010) 305-314. 